\title{
Real-Time GPS/Galileo Precise Point Positioning Using NAVCAST Real-Time Corrections
}

\author{
Abdelsatar Elmezayen*, Ahmed El-Rabbany \\ Department of Civil Engineering, Ryerson University, Toronto, Canada \\ Email: *abdelsatar.elmezayen@ryerson.ca, rabbany@ryerson.ca
}

How to cite this paper: Elmezayen, A. and El-Rabbany, A. (2019) Real-Time GPS/Galileo Precise Point Positioning Using NAVCAST Real-Time Corrections. Positioning, 10, 35-49.

https://doi.org/10.4236/pos.2019.103003

Received: July 30, 2019

Accepted: August 28, 2019

Published: August 31, 2019

Copyright $\odot 2019$ by author(s) and Scientific Research Publishing Inc. This work is licensed under the Creative Commons Attribution International License (CC BY 4.0).

http://creativecommons.org/licenses/by/4.0/ (c) (i) Open Access

\begin{abstract}
Real-time precise point positioning (PPP) is possible through the use of real-time precise satellite orbit and clock corrections, which are available through a number of organizations including the International GNSS Service (IGS) real-time service (IGS-RTS). Unfortunately, IGS-RTS is only available for the GPS and GLONASS constellations. In 2018, a new real-time service, NAVCAST, which provides real-time precise orbit and clock corrections for the GPS and Galileo constellations, was launched. In this research, the potential performance of real-time PPP which makes use of NAVCAST real-time corrections is analyzed using various static and kinematic datasets. In the static dataset, 24 hours of observations from eight IGS stations in Canada over three different days were utilized. The static results show that the contribution of Galileo satellites can improve the positioning accuracy, with $30 \%$, $34 \%$, and $31 \%$ in east, north, and up directions compared to the GPS-only counterparts. In addition, centimeter-level positioning accuracy in the horizontal direction and decimeter-level positioning accuracy in the vertical direction can be achieved by adding Galileo observations. In the kinematic dataset, a real vehicular test was conducted in urban and suburban combined areas. The real-time kinematic GPS/Galileo PPP solutions demonstrate an improvement of about $53 \%, 45 \%$, and $70 \%$ in east, north, and up directions compared to the GPS-only counterparts. It is shown that the real-time GPS/Galileo PPP can achieve a sub-decimeter horizontal positioning accuracy and about meter-level vertical positioning accuracy through the use of NAVCAST real-time corrections.
\end{abstract}

\section{Keywords}

NAVCAST, Static, Kinematic, GPS/Galileo PPP

\section{Introduction}

Real-time kinematic (RTK) positioning is one of the most widely used survey- 
ing techniques [1]. With RTK, centimeter-level positioning accuracy can be achieved, which makes this technique the standard choice for precise navigation applications such as machine automation, surveying, and mapping [2] [3]. User position is determined in the RTK technique by using data transferred from a reference station, which includes distance dependent errors such as tropospheric delay, ionospheric delay, and satellite orbit errors. Due to the fact that these errors are spatially less correlated for long baselines, the distance between the reference station and the user should not exceed about $15 \mathrm{~km}$ [4]. Network RTK (NRTK) technique, which employs a network of reference stations offers the possibility of not only increasing the distance between the rover and the reference stations, but also enhancing the reliability of the RTK technique [1] [4]. One of the most common modes of the NRTK technique is the virtual reference station (VRS) system. The main concept of VRS is to generate a virtual reference station, which is located several meters away from the user, together with the raw data [1]. The user receiver sends its approximate position through cellular data link to the computing server, and then corrections are sent back to the user receiver in a Radio Technical Commission for Maritime services (RTCM) format in order to determine the positioning solution. In this technique, at least three reference stations are required to generate the virtual station data, which limits its usage for specific areas that have a dense network of GNSS stations [1] [5].

Alternatively, precise point positioning (PPP) provides positioning solution accuracy at the centimeter-level in static mode and at the decimeter-level in kinematic mode for a single GNSS receiver using international GNSS service (IGS) rapid or final precise ephemeris [6] [7] [8] [9]. However, the required high positioning accuracy can only be achieved in post-processing mode due to the latency of the precise ephemeris [10]. In order to meet the growing needs for reliable real-time PPP, a real-time working group (RTWG) was established by IGS in 2001 and a real-time service (IGS-RTS) project was initially operated in 2011 in order to provide precise orbit and clock products and GNSS observations [11]. IGS-RTS provides GPS only or GPS + GLONASS real-time precise orbit and clock corrections [12]. Additionally, there are several analysis centers that provide real-time corrections for multi-constellation GNSS as a free service [12], namely German Federal Agency for Cartography and Geodesy (BKG), Centre National d'Etudes Spatiales (CNES), German Aerospace Centre (DLR), European Space Agency's Space Operations Centre in Darmstadt, Germany (ESA/ESOC), Deutsches GeoForschungs Zentrum (GFZ), GMV Aerospace and Defense (GMV), Natural Resources Canada (NRCAN), and Wuhan University WUHAN. Real-time PPP was assessed for static and kinematic applications using GPS only [13], GPS + GLONASS [14], GPS + GLONASS + BeiDou [15], and GPS + GLONASS + Galileo + BeiDou [10] [16] [17]. Galileo-only PPP and its contribution to GPS PPP were investigated using the final precise ephemeris for both static and post-processed kinematic modes [18]. The study showed that Galileo-only PPP achieved positioning accuracies at the centimeter-level and de- 
cimeter-level after convergence for static and post-processed kinematic modes, respectively. Additionally, the convergence time for the GPS/Galileo PPP was reduced in comparison with the GPS-only PPP. The performance of real-time PPP using GPS/Galileo was assessed using simulated real-time GNSS products in static mode [19]. In a simulated open-sky environment, centimeter-level positioning accuracy was achieved. In October 2018, Spaceopal GmbH Company, the prime contractor responsible for the Galileo operations, launched a new GNSS high accuracy positioning service (NAVCAST) [20]. This service provides GPS and Galileo real-time orbit and clock corrections in addition to broadcast ephemeris for both the satellite systems. Using the NAVCAST products and GPS/Galileo dual frequency observations, positioning accuracy at the centimeter-level can be achieved in static mode [21].

In this study, the real-time GPS/Galileo PPP performance is assessed based on NAVCAST real-time corrections. The GPS and Galileo observations from eight IGS stations in Canada over three days were used for static PPP performance assessment. Additionally, a real road test was carried out in order to investigate the real-time kinematic PPP capabilities. In the following section, the processing strategy used in BKG Network Transport of RTCM via Internet Protocol (NTRIP) client (BNC) software is described. NAVCAST real-time stream description and numerical results for both of the static and kinematic tests are presented in the consecutive sections. The conclusions are presented in the final section.

\section{Mathematical Models and Processing Strategy in BNC}

The new version of BNC software, v2.12.9, is used in this research, due to its new ability to process multi-constellation GNSS observations in Rinex 3.03 format and combining real-time orbit and clock corrections with broadcast ephemeris in real-time mode [22]. In order to account for the ionospheric delay, un-differenced ionosphere-free (IF) linear combinations of GPS and Galileo pseudorange and carrier phase measurements are employed as described in Equations (1)-(4).

$$
\begin{gathered}
P_{I F}^{G}=\rho^{G}+c \times d t_{r}^{G}-c \times d t_{s}^{G}+T^{G}+\varepsilon_{P I F}^{G} \\
\Phi_{I F}^{G}=\rho^{G}+c \times d t_{r}^{G}-c \times d t_{s}^{G}+T^{G}+N_{I F}^{G}+\varepsilon_{P I F}^{G} \\
P_{I F}^{E}=\rho^{E}+c \times d t_{r}^{G}-c \times d t_{s}^{E}+T^{E}+I S B+\varepsilon_{P I F}^{E} \\
\Phi_{I F}^{E}=\rho^{E}+c \times d t_{r}^{G}-c \times d t_{s}^{E}+T^{E}+N_{I F}^{E}+I S B+\varepsilon_{P I F}^{E},
\end{gathered}
$$

where, $G$ and $E$ refer to GPS and Galileo, respectively; $\rho^{G}, \rho^{E}$ are the geometric range between the receiver and corresponding satellite; $c$ is the speed of light; $d t_{r}^{G}$ is the GPS receiver clock error, which includes the GPS IF linear combination of receiver code hardware delay; $d t_{s}^{G}$ and $d t_{s}^{E}$ are the satellite clock errors for GPS and Galileo, respectively, which include the GPS/Galileo IF linear combination of satellite code hardware delay; $T^{G}$ and $T^{E}$ are the total tropospheric delay for GPS and Galileo, respectively; $N_{I F}^{G}$ and $N_{I F}^{E}$ are the 
non-integer IF ambiguity terms for GPS and Galileo, respectively, which are a combination of the GPS/Galileo IF linear combinations of satellite code hardware delay, satellite phase hardware delay, receiver code hardware delay, and receiver phase hardware delay; ISB refers to the inter-system bias between the Galileo and GPS satellite systems, which equal the difference between the GPS and Galileo IF linear combination of satellite code hardware delay; $\varepsilon$ accounts for random and un-modeled errors.

GPS satellites clock correction includes the IF linear combination of satellites code hardware delays on L1/L2. Likewise, Galileo satellites clock correction includes the IF linear combination of satellites code hardware delays on E1/E5a. In order to be consistent with GPS satellites clock correction, GPS IF linear combination of pseudorange measurements is corrected by $D C B_{P 1-C 1}$. Additionally, the zenith dry component of the tropospheric delay is accounted for using the Saastamoinen model. The IF linear combination of pseudorange and carrier phase measurements after accounting for all related errors for GPS and Galileo are summarized in Equations (5)-(8).

$$
\begin{gathered}
P_{I F}^{\prime G}=\rho^{G}+b_{r}^{G}-c \times d t_{s}^{G}+m_{w}^{G} \times z w d^{G}+\varepsilon_{P I F}^{G} \\
\Phi_{I F}^{\prime G}=\rho^{G}+b_{r}^{G}-c \times d t_{s}^{G}+m_{w}^{G} \times z w d^{G}+N_{I F}^{G}+\varepsilon_{P I F}^{G} \\
P_{I F}^{\prime E}=\rho^{E}+b_{r}^{G}-c \times d t_{s}^{E}+m_{w}^{E} \times z w d^{E}+I S B+\varepsilon_{P I F}^{E} \\
\Phi_{I F}^{\prime E}=\rho^{E}+b_{r}^{G}-c \times d t_{s}^{E}+m_{w}^{E} \times z w d^{E}+N_{I F}^{E}+I S B+\varepsilon_{P I F}^{E}
\end{gathered}
$$

where the prime ( $)$ refers to the corrected measurements; zwd is the zenith wet delay; $m_{w}$ is the wet mapping function; $b_{r}^{G}=c \times d t_{r}^{G}$. In BNC software, extended Kalman filter (EKF) is implemented to estimate the state vector, which in our case includes three coordinates, receiver clock error, zenith wet tropospheric delay, ISB, and non-integer ambiguities for the tracked satellites.

\section{NAVCAST Real-Time Stream Description}

NAVCAST GNSS PPP service was announced on October 29, 2018 by Spaceopal, GmbH Company, the prime contractor responsible for Galileo operations [20]. It provides GPS and Galileo orbit and clock corrections to be used with broadcast ephemeris in order to convert it to precise ephemeris. The Orbit and clock corrections are given in the satellite orbital plane (radial, along track, and across track) and need to be transformed to Earth-centered Earth-fixed (ECEF) coordinate system as described in [13] before applying it to broadcast ephemeris. These products are obtained based on the real-time clock estimation algorithm (RETICLE) developed by the German Aerospace Centre (DLR) [23] [24]. NAVCAST products include GPS/Galileo orbit and clock corrections that are broadcasted every 30 and 5 seconds, respectively. The only requirement to use this service is to register through the Spaceopal website (https://spaceopal.com/navcast/). In order to receive the NAVCAST corrections and broadcast ephemeris in real time, NTRIP client software is needed. The BKG NTRIP client (BNC) software, which is available through the BKG website [25], can be used to combine the NAVCAST correc- 
tions, broadcast ephemeris, and GNSS observations to provide PPP solution in real time. Additionally, the BNC software can be used to save NAVCAST corrections to be used in a real-time PPP processing mode. The main specifications of the NAVCAST correction streams are summarized in Table 1 and Table 2.

\section{Static Test Data Collection}

The static test was carried using observations from eight IGS stations in Canada. The Observations were obtained for eight hours with a 30-second sampling interval on 24, 27, and 28 of June, 2019 using the download active control system data tool, which is available on NRCAN website. The eight-hour time windows were chosen to be from $0 \mathrm{~h}$ to $8 \mathrm{~h}$ on the first day, from $8 \mathrm{~h}$ to $16 \mathrm{~h}$ on the second day, and from $16 \mathrm{~h}$ to $24 \mathrm{~h}$ on the third day, in order to assess the consistency of the real-time PPP solutions using the NAVCAST real-time corrections. The chosen stations were ALBH, ALGO, DUBO, NRC1, PRDS, SCH2, STJO, and YELL as shown in Figure 1. The NAVCAST real-time broadcast ephemeris, orbit and clock corrections were saved using the BNC software. The detailed strategy of PPP in BNC used in this research is the same as in [15] and the positioning errors are modeled as a random walk process with spectral densities zero in the horizontal and vertical directions, as the processing mode is static.

Table 1. CLKA0_DEU mount point specifications (https://spaceopal.com/navcast/).

\begin{tabular}{lll}
\hline Reference point & APC & \\
Reference frame & ITRF2008 & \\
Format & RTCM_3.1 & \\
Satellites constellations & GPS + Galileo & \\
RTCM messages & Constellation & Orbit and clock corrections \\
& GPS & 1057, 1058 \\
& Galileo & 1040, 1041 \\
Caster IP: port/NTRIP version & navcast.spaceopal.com: 443/2s \\
Analysis Centre & German Aerospace Centre (DLR) \\
\hline
\end{tabular}

Table 2. BCEP0_DEU1 mount point specifications (https://spaceopal.com/navcast/).

\begin{tabular}{lll}
\hline Reference point & BCEP0_DEU1-BCE \\
Format & RTCM_3.3 & \\
Satellites constellations & GPS + Galileo & \\
RTCM messages & Constellation & Navigation \\
& GPS & 1019 \\
& Galileo & 1044,1045 \\
Caster IP: port / NTRIP version & navcast.spaceopal.com: 443/2s \\
Analysis Centre & German Aerospace Centre (DLR)
\end{tabular}




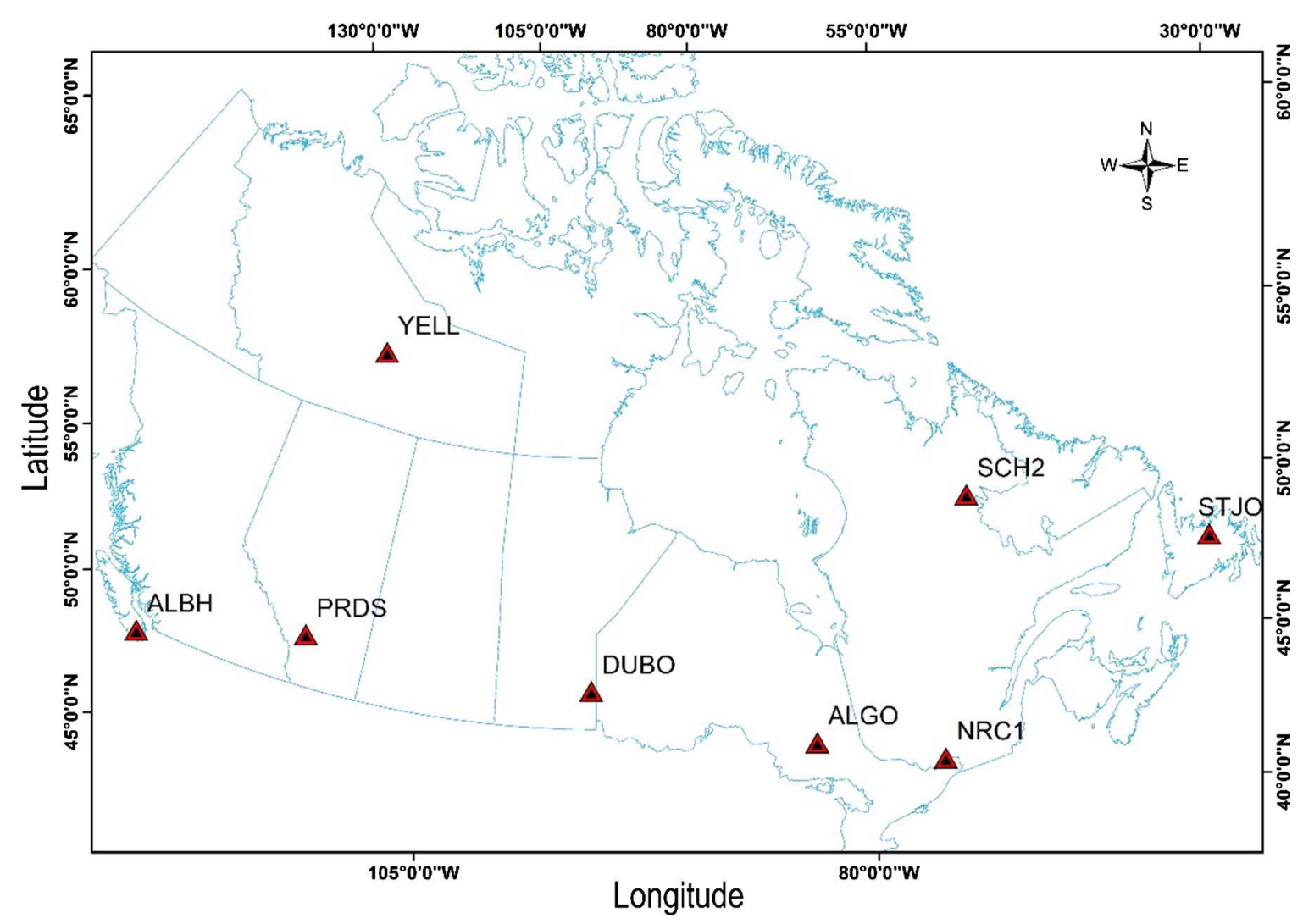

Figure 1. The eight IGS stations chosen for the static test.

\section{Assessment of Real-Time PPP Using the Static Dataset}

The observations from the selected IGS stations for the three different days were processed using the BNC software in two different configurations, namely GPS only and GPS/Galileo PPP in real-time mode. For both configurations, the NAVCAST pre-saved broadcast ephemeris along with orbit and clock corrections were used to account for the orbit and clock errors. The positioning performance was assessed through the comparison with the published coordinates of the used IGS stations. The positioning results for NRC1 and ALGO stations for the first and the second days are presented in Figures 2-5. It can be seen that the number of visible satellites is increased, leading to low PDOP values as shown in Figure 2 and Figure 4. Moreover, the addition of Galileo observations enhances the positioning solution accuracy and reduces the convergence period significantly. The root mean square (RMS) of the resulted positioning errors for the used IGS stations in the east, north, and up directions are presented in Table 3. The positioning accuracy for GPS/Galileo PPP is enhanced with about $30 \%$, $34 \%$, and $31 \%$ in the east, north, and up directions compared to GPS-only PPP. The overall positioning accuracy is $0.04 \mathrm{~m}, 0.02 \mathrm{~m}$, and $0.108 \mathrm{~m}$ in the east, north, and up directions for GPS/Galileo PPP compared to $0.06 \mathrm{~m}, 0.03 \mathrm{~m}$, and $0.147 \mathrm{~m}$ in the east, north, and up directions for GPS-only PPP. Moreover, the positioning results show similar accuracy over the three days, which is an indication of the reliability of the NAVCAST real-time products. 
Table 3. RMS of positioning errors for static datasets.

\begin{tabular}{|c|c|c|c|c|c|c|c|}
\hline \multirow{2}{*}{\multicolumn{2}{|c|}{ Stations }} & \multicolumn{2}{|r|}{ East } & \multicolumn{2}{|c|}{ North } & \multicolumn{2}{|r|}{ Up } \\
\hline & & GPS & GPS/Galileo & GPS & GPS/Galileo & GPS & GPS/Galileo \\
\hline \multirow{8}{*}{ First day } & ALBH & 0.047 & 0.036 & 0.032 & 0.024 & 0.256 & 0.106 \\
\hline & ALGO & 0.095 & 0.087 & 0.024 & 0.017 & 0.154 & 0.091 \\
\hline & DUBO & 0.113 & 0.086 & 0.026 & 0.017 & 0.139 & 0.115 \\
\hline & NRC1 & 0.055 & 0.027 & 0.041 & 0.018 & 0.098 & 0.074 \\
\hline & PRDS & 0.047 & 0.047 & 0.051 & 0.037 & 0.188 & 0.121 \\
\hline & $\mathrm{SCH} 2$ & 0.093 & 0.045 & 0.037 & 0.025 & 0.100 & 0.073 \\
\hline & STJO & 0.021 & 0.029 & 0.023 & 0.016 & 0.078 & 0.094 \\
\hline & YELL & 0.062 & 0.026 & 0.040 & 0.019 & 0.154 & 0.107 \\
\hline \multirow[t]{4}{*}{ Average (first) } & & 0.067 & 0.047 & 0.034 & 0.021 & 0.146 & 0.097 \\
\hline & ALBH & 0.031 & 0.018 & 0.037 & 0.016 & 0.146 & 0.131 \\
\hline & ALGO & 0.096 & 0.033 & 0.017 & 0.017 & 0.178 & 0.089 \\
\hline & DUBO & 0.074 & 0.038 & 0.037 & 0.023 & 0.149 & 0.116 \\
\hline \multirow{5}{*}{ Second day } & NRC1 & 0.017 & 0.016 & 0.025 & 0.018 & 0.065 & 0.024 \\
\hline & PRDS & 0.040 & 0.034 & 0.041 & 0.022 & 0.152 & 0.134 \\
\hline & $\mathrm{SCH} 2$ & 0.026 & 0.036 & 0.028 & 0.023 & 0.168 & 0.152 \\
\hline & STJO & 0.032 & 0.030 & 0.023 & 0.021 & 0.172 & 0.135 \\
\hline & YELL & 0.042 & 0.047 & 0.022 & 0.014 & 0.149 & 0.139 \\
\hline \multicolumn{2}{|l|}{ Average (second) } & 0.045 & 0.031 & 0.029 & 0.019 & 0.147 & 0.115 \\
\hline \multirow{8}{*}{ Third day } & ALBH & 0.092 & 0.025 & 0.028 & 0.031 & 0.115 & 0.114 \\
\hline & ALGO & 0.088 & 0.054 & 0.037 & 0.016 & 0.177 & 0.129 \\
\hline & DUBO & 0.060 & 0.042 & 0.038 & 0.020 & 0.169 & 0.140 \\
\hline & $\mathrm{NRC1}$ & 0.081 & 0.074 & 0.025 & 0.021 & 0.088 & 0.041 \\
\hline & PRDS & 0.029 & 0.029 & 0.024 & 0.020 & 0.188 & 0.156 \\
\hline & $\mathrm{SCH} 2$ & 0.056 & 0.050 & 0.030 & 0.019 & 0.139 & 0.128 \\
\hline & STJO & 0.070 & 0.047 & 0.011 & 0.010 & 0.134 & 0.133 \\
\hline & YELL & 0.024 & 0.011 & 0.033 & 0.023 & 0.173 & 0.147 \\
\hline Average (third) & & 0.062 & 0.041 & 0.028 & 0.020 & 0.148 & 0.113 \\
\hline Average (overall) & & 0.057 & 0.040 & 0.030 & 0.020 & 0.147 & 0.108 \\
\hline
\end{tabular}

In order to assess the convergence behavior of the obtained real-time positioning solution, The distribution of the positioning errors based on all selected IGS stations for all-time windows in the east, north, and up directions for GPS/Galileo PPP are presented in Figures 6-8, respectively. After 20 minutes, $94.25 \%$ of the positioning errors in the east direction are less than $0.3 \mathrm{~m}, 100 \%$ of the positioning errors in the north direction are less than $0.2 \mathrm{~m}$, and $96.63 \%$ of the positioning errors in the up direction are less than $0.3 \mathrm{~m}$. By the end of the 

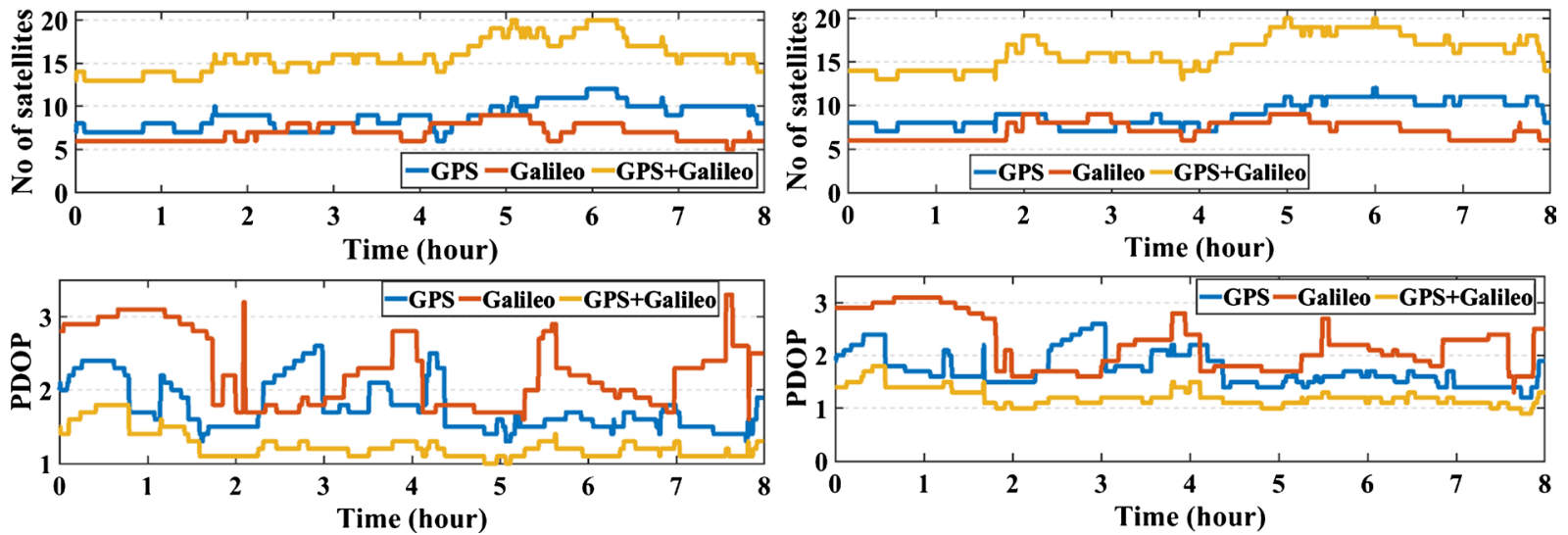

Figure 2. Satellites visibility and PDOP values at ALGO (left) and NRC1 (right) for the first day.
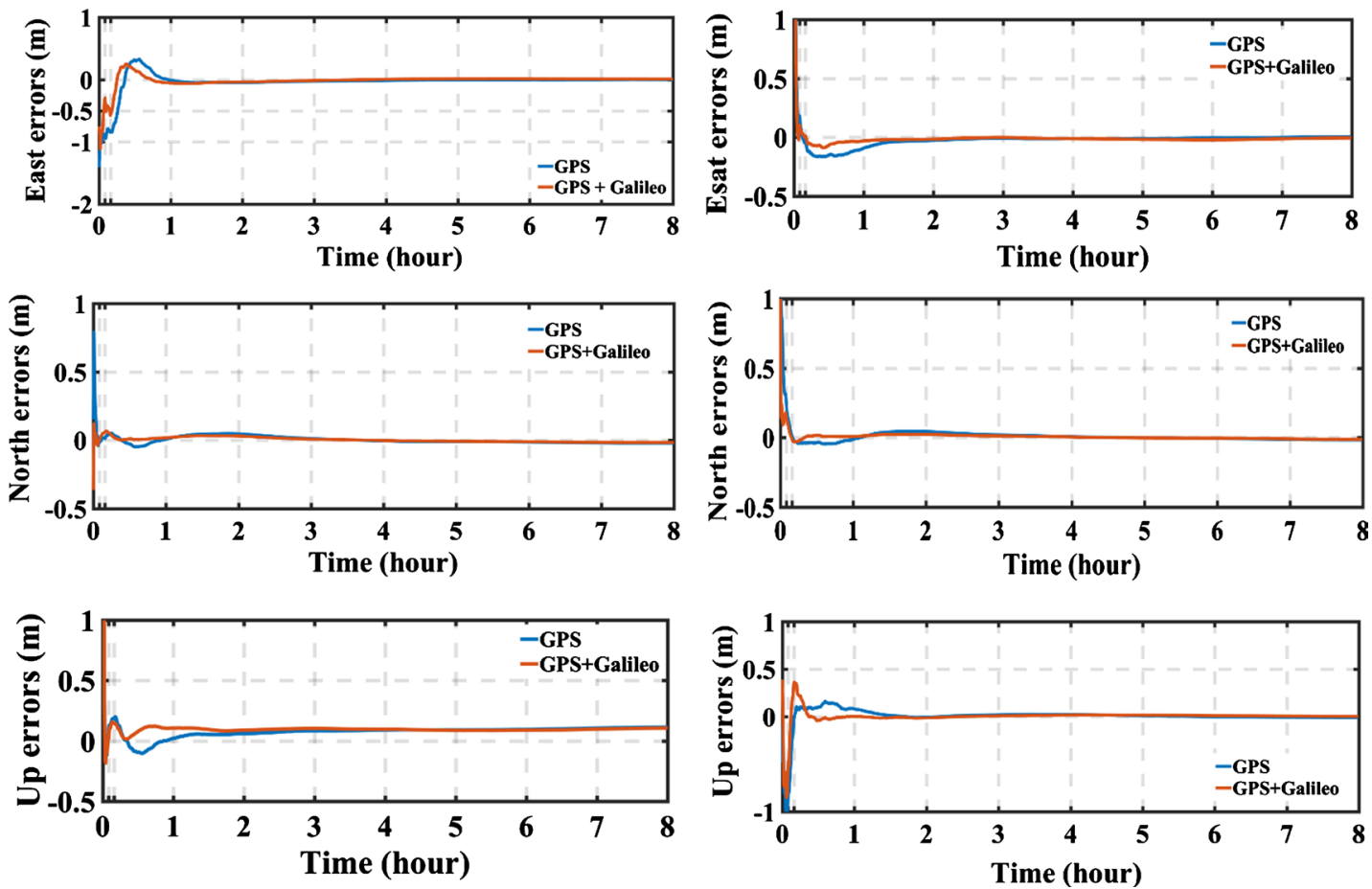

Figure 3. Positioning errors at ALGO (left) and NRC1 (right) for the first day.
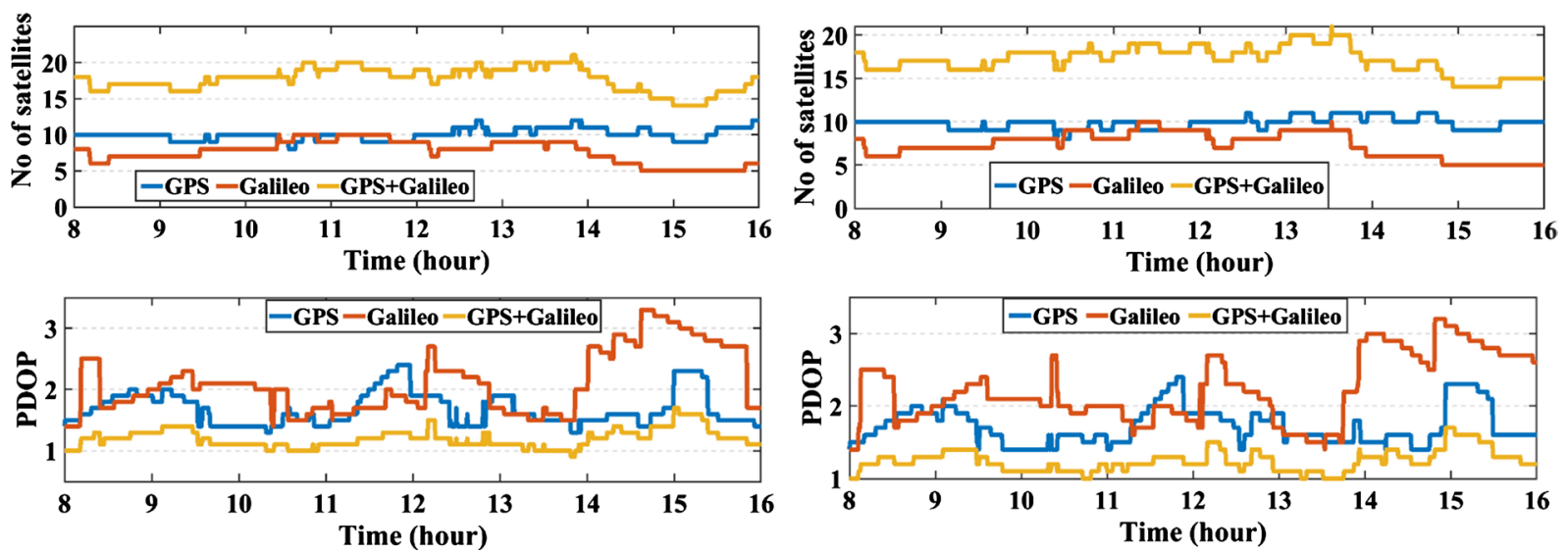

Figure 4. Satellites visibility and PDOP values at ALGO (left) and NRC1 (right) for the second day. 

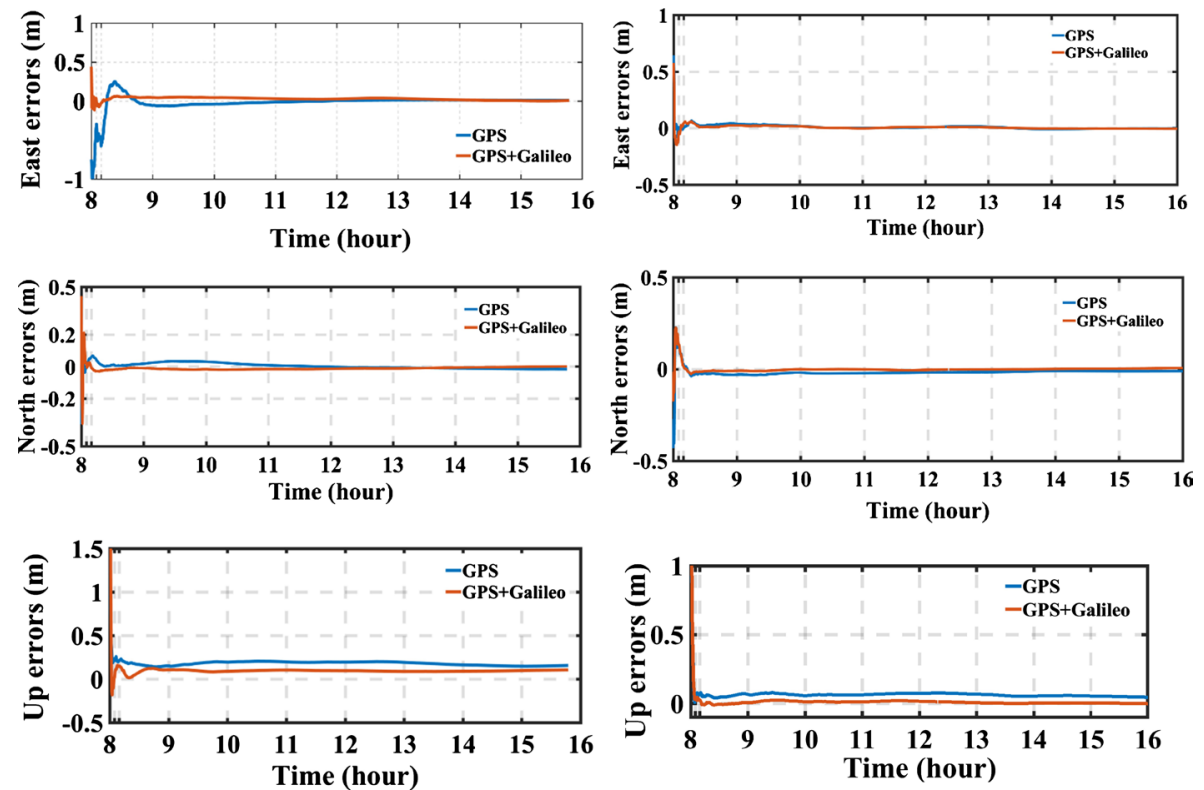

Figure 5. Positioning errors at ALGO (left) and NRC1 (right) for the second day.

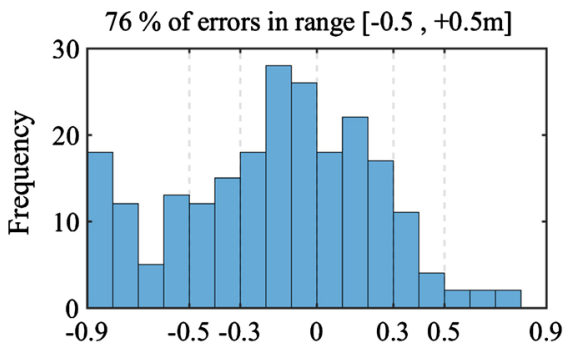

East errors (m), after 5 minutes

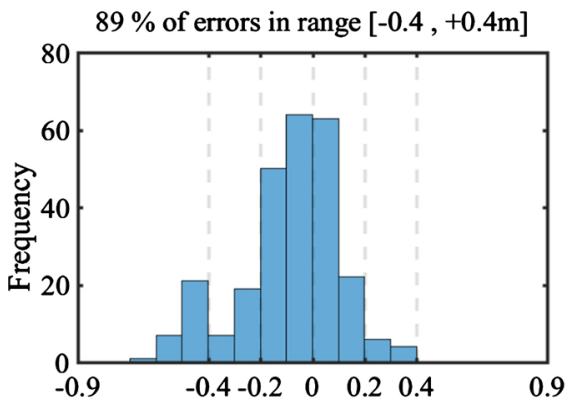

East errors (m), after 10 minutes

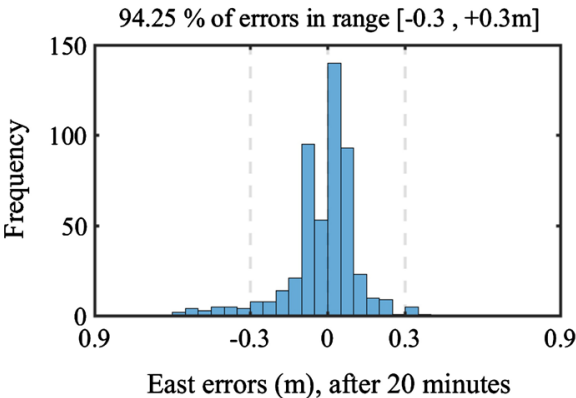

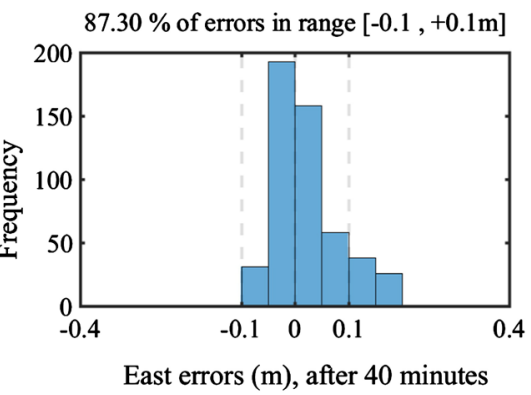
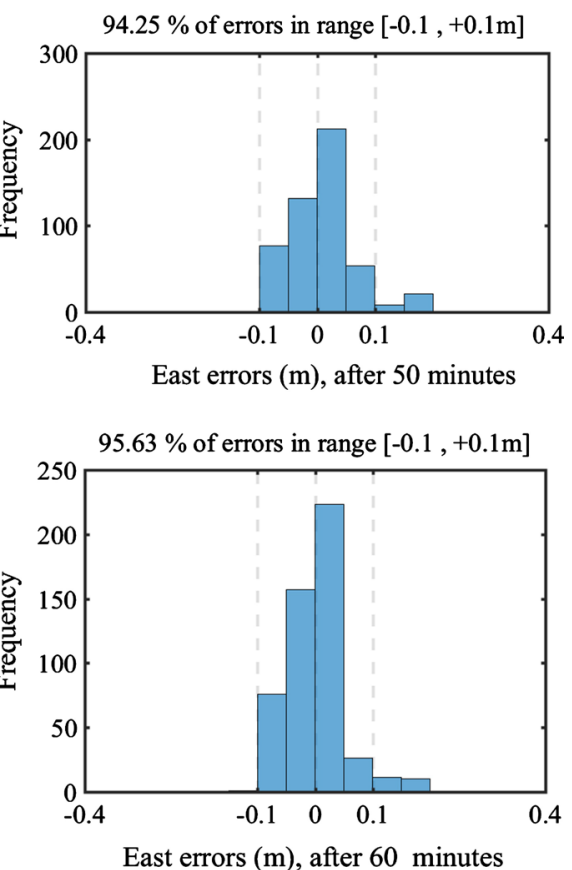

Figure 6. Positioning errors distribution in east direction. 

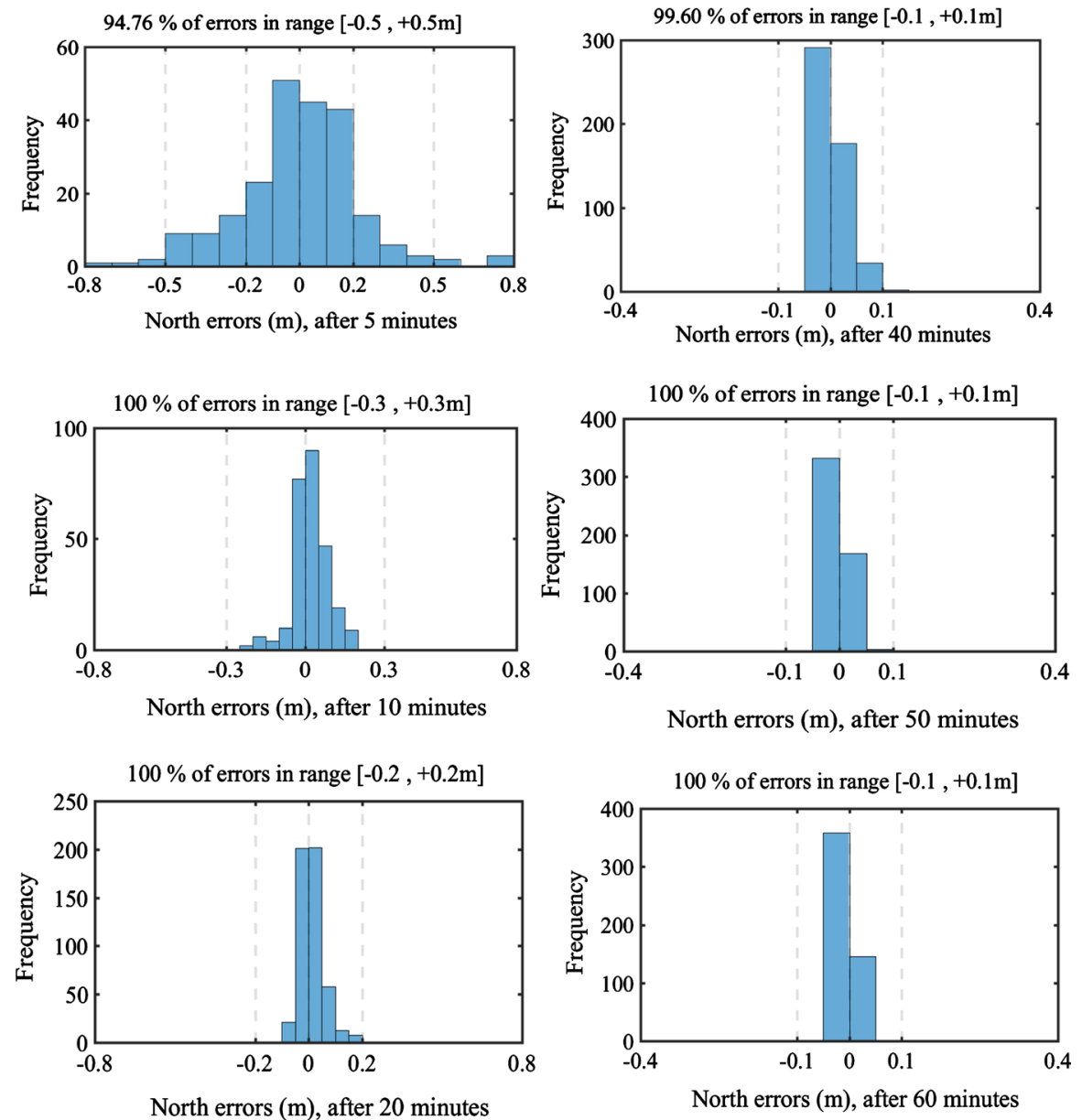

Figure 7. Positioning errors distribution in north direction.

first hour of observation, $95.63 \%$ of the positioning errors in the east direction are less than $0.1 \mathrm{~m}, 100 \%$ of the positioning errors in the north direction are less than $0.1 \mathrm{~m}$, and $97.42 \%$ of the positioning errors in the up direction are less than $0.2 \mathrm{~m}$.

\section{Kinematic Test}

To further assess the real-time GPS/Galileo PPP solutions accuracy, kinematic land vehicular test was conducted for about forty minutes in Toronto, Canada on July 19, 2019. The test trajectory included urban and suburban combined areas with several overpasses bridges as shown in Figure 9. The GPS and Galileo observations were collected using Trimble R9s GNSS geodetic receiver, while the real-time products were saved using BNC software through NTRIP. The reference positioning solution was obtained from carrier-phase-based DGNSS solution, which was created using Trimble Business Centre (TBC) V.5.0 software. The reference GNSS station was TORO station, which is one of Cansel's GNSS permanent network (CAN-NET) in the Toronto area with a baseline of about 16 $\mathrm{km}$. The detailed strategy of PPP in BNC used in this research is the same as in [15] and the positioning errors are modeled as a random walk process with spectral densities $100 \mathrm{~m}^{2} / \mathrm{s}$ in the horizontal and vertical directions. 

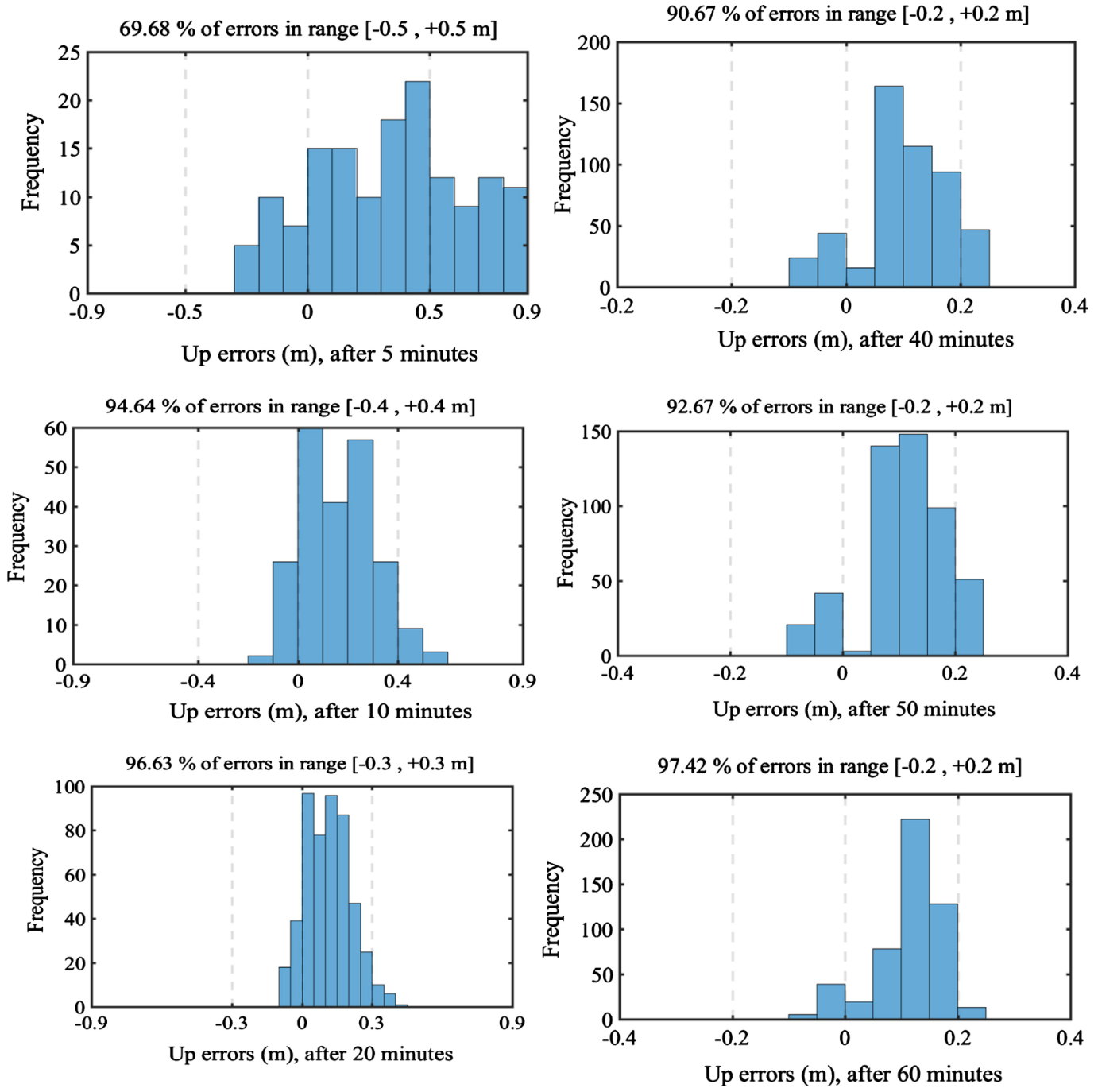

Figure 8. Positioning errors distribution in up direction.
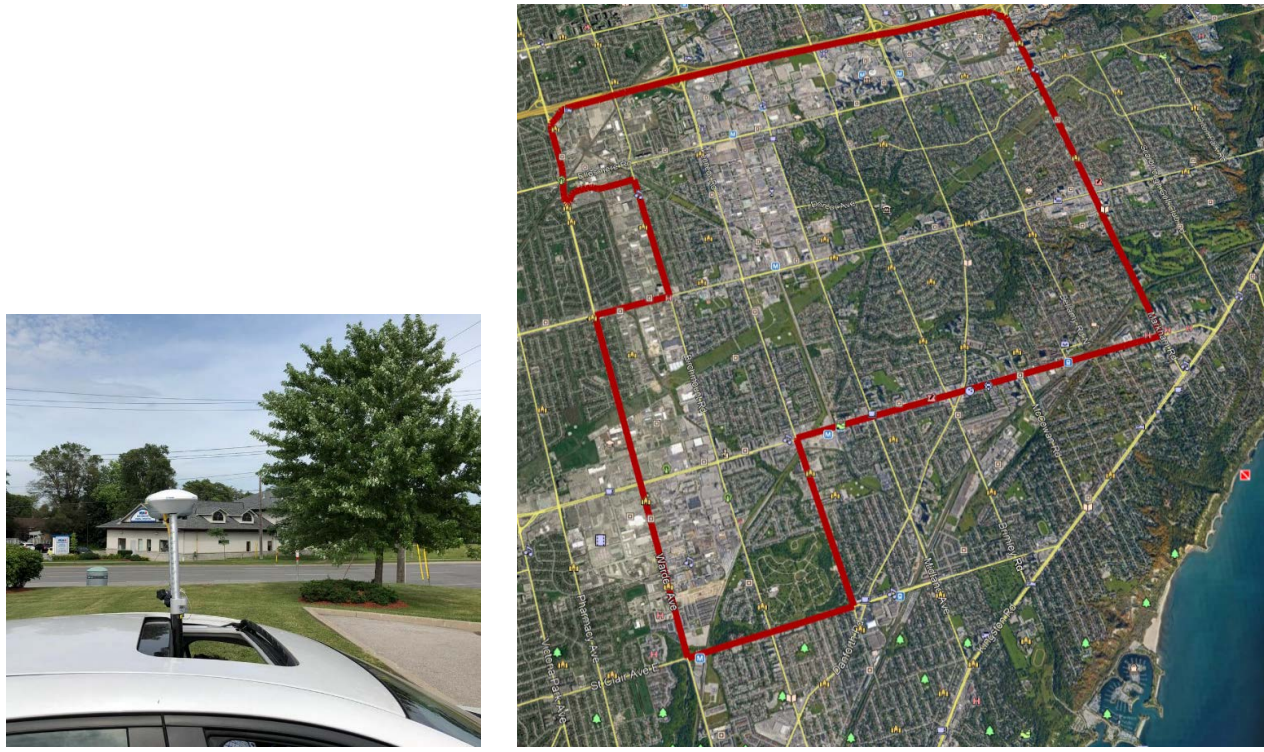

Figure 9. Kinematic test set up (left), and trajectory (right), Toronto, Ontario, Canada. 
The GPS/Galileo observations along with the pre-saved NAVCAST corrections and broadcast ephemeris were processed in real-time mode using the BNC software in two different configurations, namely GPS-only and GPS/Galileo PPP. The DGNSS positioning solutions with fixed-ambiguity parameters were used as a reference for assessing the PPP solutions. The DGNSS solutions were converted from NAD83 to ITRF reference frames in order to be consistent with the obtained real-time PPP solutions. As shown in Figure 10 and Figure 11, the number of satellites is significantly increased by adding Galileo satellites, leading to a significantly lower PDOP value. The positioning errors in the east, north, and up directions are shown in Figures 12-14. The real-time GPS/Galileo PPP solutions are more stable in comparison with the GPS PPP counterparts. The positioning errors for the GPS/Galileo PPP solution are within \pm 1 meter for the east, north, and up directions. However, there are some spikes in the positioning errors where the PPP solution starts to re-converge after GNSS outages, which occurred because of signal blockage while passing under the bridges. In contrast, the GPS-only PPP errors can reach several meters, which is essentially due to the low number of visible GPS satellites and the bad satellites geometry as shown in Figure 10 and Figure 11.

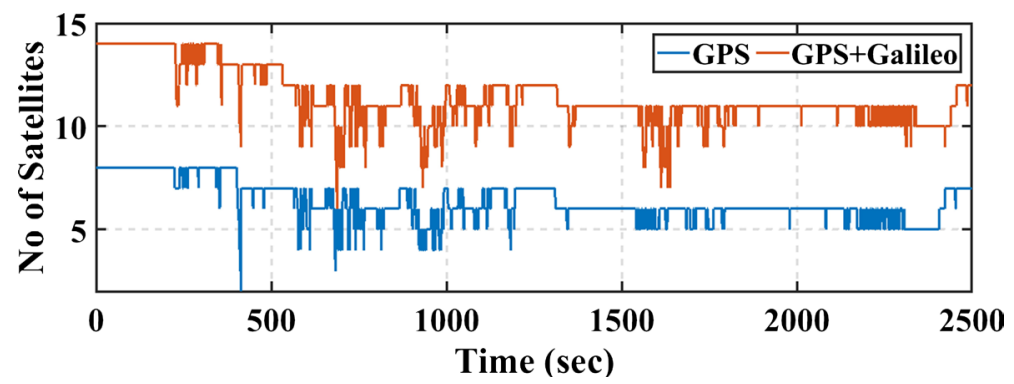

Figure 10. Satellites visibility for the whole trajectory.

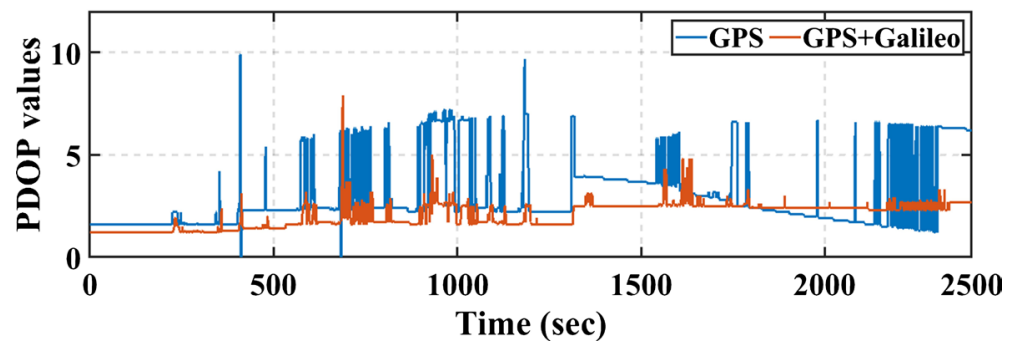

Figure 11. PDOP values for the whole trajectory.

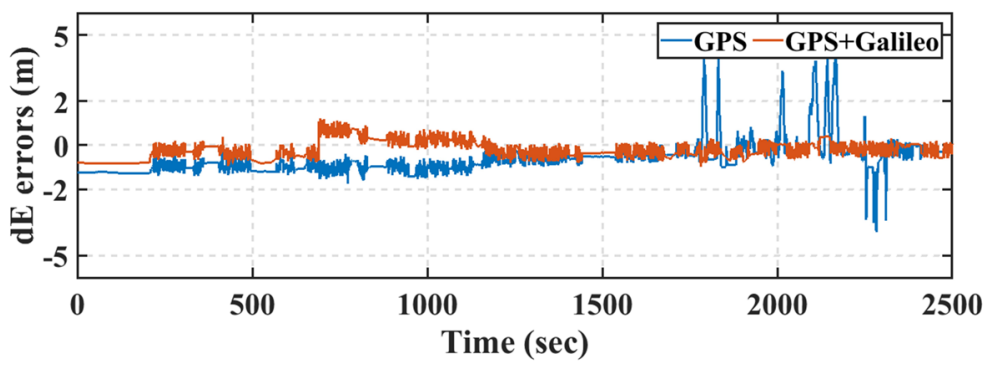

Figure 12. Positioning errors in east direction for the kinematic test. 


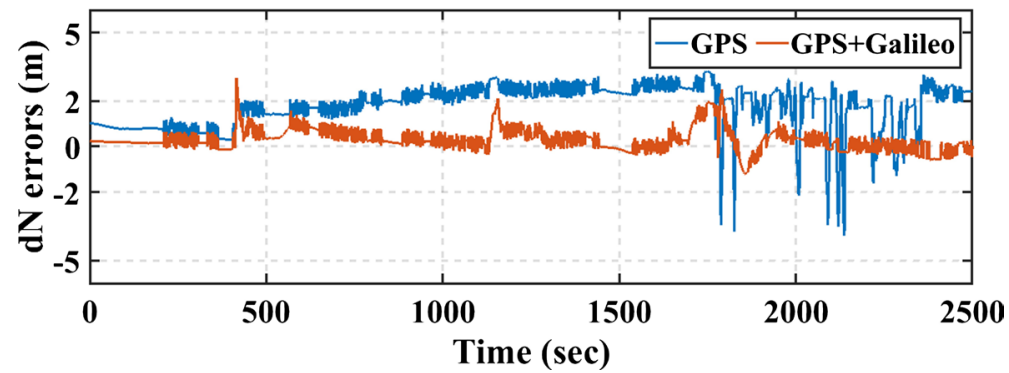

Figure 13. Positioning errors in north direction for the kinematic test.

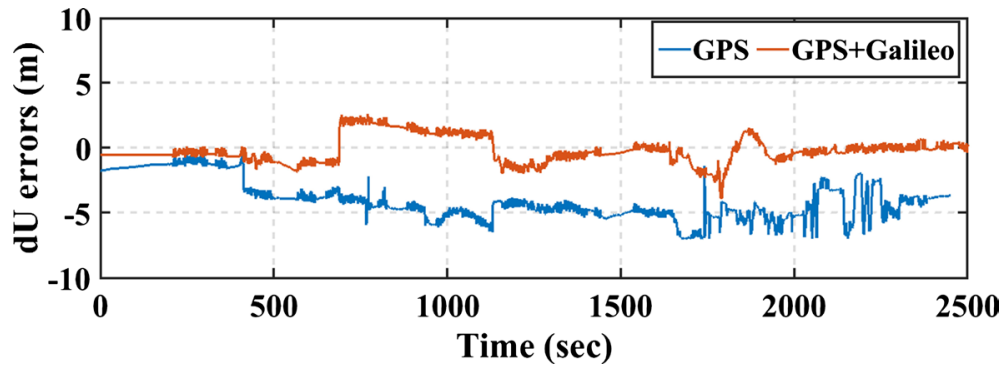

Figure 14. Positioning errors in up direction for the kinematic test.

Table 4. Mean and RMS for East, North, and Up components for the kinematic test.

\begin{tabular}{ccccccc}
\hline \multirow{2}{*}{ Constellation } & \multicolumn{2}{c}{$\mathrm{dE}(\mathrm{m})$} & \multicolumn{2}{c}{$\mathrm{dN}(\mathrm{m})$} & \multicolumn{2}{c}{$\mathrm{dU}(\mathrm{m})$} \\
\cline { 2 - 7 } & mean & RMS & mean & RMS & mean & RMS \\
\hline GPS & 0.605 & 0.978 & 1.815 & 1.054 & 4.057 & 3.334 \\
GPS+Galileo & 0.224 & 0.457 & 0.288 & 0.574 & 0.189 & 0.998 \\
\hline
\end{tabular}

The RMS of both of the GPS PPP and GPS/Galileo PPP solution components are presented in Table 4. The real-time kinematic PPP solutions accuracy can be improved by about $53 \%, 45 \%$, and $70 \%$ in the east, north, and up directions by combining GPS and Galileo observations. The overall positioning accuracy is $0.457 \mathrm{~m}, 0.574 \mathrm{~m}$, and $0.998 \mathrm{~m}$ in the east, north, and up directions for GPS/Galileo PPP compared to $0.978 \mathrm{~m}, 1.054 \mathrm{~m}$, and $3.334 \mathrm{~m}$ in the east, north, and up directions for GPS PPP.

\section{Conclusion}

In this research, the performance of real-time GPS/Galileo PPP, which makes use of NAVCAST corrections, has been assessed using various static and kinematic datasets. GPS and Galileo observations from eight IGS stations in Canada, along with the pre-saved NAVCAST real-time products, over three different days have been processed in the real-time mode using the BNC software. It has been shown that the accuracy of the real-time GPS/Galileo PPP solution is in the order of $0.04 \mathrm{~m}, 0.02 \mathrm{~m}$, and $0.108 \mathrm{~m}$ in the east, north, and up directions, respectively. In addition, the GPS/Galileo PPP accuracy has improved by about $30 \%, 34 \%$, and $31 \%$ in the east, north, and up directions, respectively, in comparison with the GPS-only PPP counterpart. Moreover, the real-time kinematic 
GPS/Galileo PPP solution has achieved sub-decimeter-level horizontal positioning accuracy and about one meter-level vertical positioning accuracy. Furthermore, the positioning accuracy of the real-time kinematic GPS/Galileo PPP solution has improved by about 53\%, 45\%, and 70\% in the east, north, and up directions, respectively, in comparison with the GPS-only PPP counterpart.

\section{Acknowledgements}

This research is supported by the Government of Ontario and Ryerson University through the Ontario Trillium Scholarship. The authors would like to thank the NRCAN for making the GNSS observation available. Additionally, the authors would like to thank the following: Trimble for providing them with the TBC software, Cansel Company for providing GNSS observations for TORO station, and the Spaceopal Company support team for their valuable information and for making the NAVCAST products available.

\section{Conflicts of Interest}

The authors declare no conflict of interest.

\section{References}

[1] Landau, H., Vollath, U. and Chen, X. (2002) Virtual Reference Station Systems. Journal of Global Positioning Systems, 1, 137-143. https://doi.org/10.5081/jgps.1.2.137

[2] Choy, S., Bisnath, S. and Rizos, C. (2017) Uncovering Common Misconceptions in GNSS Precise Point Positioning and Its Future Prospect. GPS Solutions, 21, 13-22. https://doi.org/10.1007/s10291-016-0545-X

[3] Rizos, C., Janssen, V., Roberts, C. and Grinter, T. (2012) Precise Point Positioning: Is the Era of Differential GNSS Positioning Drawing to an End? Proceedings of FIG Working Week, Rome, 6-10 May 2012, 1-17.

[4] Hu, G., Khoo, H., Goh, P. and Law, C. (2003) Development and Assessment of GPS Virtual Reference Stations for RTK Positioning. Journal of Geodesy, 77, 292-302. https://doi.org/10.1007/s00190-003-0327-4

[5] Li, B., Feng, Y., Shen, Y. and Wang, C. (2010) Geometry-Specified Troposphere Decorrelation for Subcentimeter Real-Time Kinematic Solutions over Long Baselines. Journal of Geophysical Research: Solid Earth, 115, 226-234. https://doi.org/10.1029/2010JB007549

[6] Kouba, J. (2015) A Guide to Using International GNSS Service (IGS) Products. https://kb.igs.org/hc/en-us/articles/201271873-A-Guide-to-Using-the-IGS-Products

[7] Kouba, J. and Héroux, P. (2001) Precise Point Positioning Using IGS Orbit and Clock Products. GPS Solutions, 5, 12-28. https://doi.org/10.1007/PL00012883

[8] Li, X., Zhang, X., Ren, X., Fritsche, M., Wickert, J. and Schuh, H. (2015) Precise Positioning with Current Multi-Constellation Global Navigation Satellite Systems: GPS, GLONASS, Galileo and BeiDou. Scientific Reports, 5, Article ID: 8328. https://doi.org/10.1038/srep08328

[9] Wang, M. and Gao, Y. (2001) A Controlled Experiment of Real-Time Precise Point Positioning for Deformation Monitoring. Proceedings of the 2008 National Technical Meeting of the Institute of Navigation, 585-594. 
[10] Wang, Z., Li, Z., Wang, L., Wang, X. and Yuan, H. (2018) Assessment of Multiple GNSS Real-Time SSR Products from Different Analysis Centers. ISPRS International Journal of Geo-Information, 7, 85. https://doi.org/10.3390/ijgi7030085

[11] Davis, J., Herring, T., Shapiro, I., Rogers, A. and Elgered, G. (1985) Geodesy by Radio Interferometry: Effects of Atmospheric Modeling Errors on Estimates of Baseline Length. Radio Science, 20, 1593-1607. https://doi.org/10.1029/RS020i006p01593

[12] IGS (2019) International GNSS Real-Time Service IGS. http://www.igs.org/rts/contributors

[13] Elsobeiey, M. and Al-Harbi, S. (2016) Performance of Real-Time Precise Point Positioning Using IGS Real-Time Service. GPS Solutions, 20, 565-571. https://doi.org/10.1007/s10291-015-0467-z

[14] Krzan, G. and Przestrzelski, P. (2016) GPS/GLONASS Precise Point Positioning with IGS Real-Time Service Products. Acta Geodynamica et Geomaterialia, 13, 69-81. https://doi.org/10.13168/AGG.2015.0047

[15] Abdi, N., Ardalan, A.A., Karimi, R. and Rezvani, M.-H. (2017) Performance Assessment of Multi-GNSS Real-Time PPP over Iran. Advances in Space Research, 59, 2870-2879. https://doi.org/10.1016/j.asr.2017.03.024

[16] Li, Z., Zhang, J., Li, T., He, X. and Wu, M. (2016) In Analysis of Static and Dynamic Real-Time Precise Point Positioning and Precision Based on SSR Correction. IEEE International Conference on Information and Automation, Ningbo, 1-3 August 2016, 2022-2027. https://doi.org/10.1109/ICInfA.2016.7832151

[17] Wang, L., Li, Z., Ge, M., Neitzel, F., Wang, Z. and Yuan, H. (2018) Validation and Assessment of Multi-GNSS Real-Time Precise Point Positioning in Simulated Kinematic Mode Using IGS Real-Time Service. Remote Sensing, 10, 337. https://doi.org/10.3390/rs10020337

[18] Xia, F., Ye, S., Xia, P., Zhao, L., Jiang, N., Chen, D. and Hu, G. (2019) Assessing the Latest Performance of Galileo-Only PPP and the Contribution of Galileo to Multi-GNSS PPP. Advances in Space Research, 63, 2784-2795. https://doi.org/10.1016/j.asr.2018.06.008

[19] Basile, F., Moore, T. and Hill, C. (2019) Analysis on the Potential Performance of GPS and Galileo Precise Point Positioning Using Simulated Real-Time Products. The Journal of Navigation, 72, 19-33. https://doi.org/10.1017/S0373463318000577

[20] Spaceopal. Spaceopal Launches Its Precise Point Positioning Service NAVCAST 2018. https://spaceopal.com

[21] Spaceopal NAVCAST: Analysing the Positioning Performance Reachable with the Precise Point Positioning (PPP) Software and the RETICLE Orbit and Clock Corrections, Munich, Germany, 2018.

[22] Stürze, A., Mervart, L., Weber, G., Rülke, A., Wiesensarter, E. and Neumaier, P. (2016) The New Version 2.12 of BKG Ntrip Client (BNC), Geophysical Research Abstracts.

[23] Hauschild, A. and Montenbruck, O. (2008) Real-Time Clock Estimation for Precise Orbit Determination of LEO-Satellites. Proceedings of the ION GNSS Meeting, 16 September 2018, 16-19.

[24] Wermuth, M., Hauschild, A., Montenbruck, O. and Kahle, R. (2012) TerraSAR-X Precise Orbit Determination with Real-Time GPS Ephemerides. Advances in Space Research, 50, 549-559. https://doi.org/10.1016/j.asr.2012.03.014

[25] BKG. German Federal Agency for Cartography and Geodesy, BNC Software. https://igs.bkg.bund.de/ntrip/bnc 